\title{
THE INHIBITION ACTION OF ETHYL-2-PHENYL HYDROZONO-3-OXOBUTYRATE ON THE CORROSION OF 6061 Al ALLOY/SiCp COMPOSITE IN HYDROCHLORIC ACID MEDIUM
}

\author{
U ACHUTHA KINI ${ }^{a}$ PRAKASH SHETTY ${ }^{b^{*}}$, S DIVAKAR SHETTY ${ }^{a}$, ARUN ISLOOR ${ }^{c}$, RAMADEV HERLE $^{a}$ \\ ${ }^{a}$ Department of Mechanical and Manufacturing Engineering, ${ }^{b}$ Department of Printing and Media Engineering , Manipal Institute of Technology, \\ Manipal - 576104, Karnataka, India \\ ${ }^{c}$ Department of Chemistry, National Institute of Technology Karnataka, Surathkal -575025, India \\ (Received: April 14, 2009 - Accepted: December 28, 2009)
}

\begin{abstract}
The inhibition behavior of ethyl-2-phenyl hydrozono-3-oxobutyrate on the corrosion of $6061 \mathrm{Al}$ alloy/SiCp composite in $0.1,0.5$ and $1 \mathrm{~N}$ hydrochloric acid solution at four different temperatures $\left(30-60^{\circ} \mathrm{C}\right)$ has been investigated using potentiostatic polarization techniques and weight loss method. The results indicated that the corrosion inhibition efficiency and the extent of surface coverage were increased with the increase in inhibitor concentration up to a critical concentration. The adsorption of the inhibitor compound on the composite surface was found to obey Temkins' and Langmuir adsorption isotherms. The potentiostatic polarization results have revealed that oxobutyrate acts as an efficient cathodic inhibitor for the corrosion of $6061 \mathrm{Al}$ alloy/SiCp composite in $\mathrm{HCl}$ medium. The thermodynamic parameters for the corrosion and adsorption processes were determined.
\end{abstract}

Keywords: Composite materials, Polarization technique, Corrosion, Adsorption.

\section{INTRODUCTION}

Aluminium, its alloys and composites represent an important category of materials due to their high technological value and wide range of applications, especially in aerospace industry and military applications. The use of these materials in light weight applications is widespread and these usages expose them to environments that could be acidic or alkaline'. Generally aluminium alloys and composites are highly resistant to corrosion owing to the formation of a protective oxide layer on their surface ${ }^{2}$. Corrosion does take place when this protective $\mathrm{Al}_{2} \mathrm{O}_{3}-3 \mathrm{H}_{2} \mathrm{O}$ layer is either unstable or defective. Corrosion in $\mathrm{Al}$ alloys and composites takes one of the two forms - pitting or intergranular corrosion. Pitting takes place in environments where the protective $\mathrm{Al}_{2} \mathrm{O}_{3}-3 \mathrm{H}_{2} \mathrm{O}$ film is partially stable. In these cases, corrosion usually originates adjacent to the flaws in the microstructure of the film ${ }^{3}$. Inter-granular corrosion results in selective corrosion at the grain boundaries or any precipitate free zones that might be found adjacent to them, with the remainder of the matrix undergoing very little corrosion. Inter-granular corrosion occurs because of the formation of precipitates along the grain boundaries, which are more anodic with respect to the interior of the grains. As a result preferential dissolution occurs at these sites where these precipitates or precipitate free zones undergo anodic reactions ${ }^{4}$.

Hydrochloric acid solutions are used for pickling, chemical and electrochemical etching and in various chemical process industries wherein aluminium alloy composites are used. In such cases it becomes very important to use corrosion inhibitors so as to protect the material against excessive corrosion $^{5,6}$. The effect of any particular organic compound on the corrosion behavior of metals in acid system depends on the type of metal and its interaction with the surface of the metal. The inhibiting action of organic compounds has been mainly attributed to adsorption of the compound on the surface of the material. This adsorption affects the electrochemical behavior involved in the corrosion process of metals/alloys/composites ${ }^{7-9}$.

The inhibition effect of 3 - methyl - 4 - amino - 5- mercapto - 1,2,4 triazole on the corrosion behavior of $6061 \mathrm{Al}$ alloy/SiCp composite has been reported ${ }^{10}$. This triazole compound was found to act as an anodic inhibitor with a maximum efficiency of $58 \%$ at $30^{\circ} \mathrm{C}$. Allyl thiourea was used as an inhibitor for the corrosion of $\mathrm{Al}$ alloy/SiCp composite in $\mathrm{HCl}$ medium and showed a maximum efficiency of $70 \%$ in the temperature range of $30-50{ }^{\circ} \mathrm{C}^{11}$.

In the present work, inhibitive action of ethyl-2-phenyl hydrozono-3oxobutyrate on the corrosion behavior of $6061 \mathrm{Al}$ alloy/SiCp composite in 0.1, 0.5 and $1 \mathrm{~N}$ hydrochloric acid medium at four different temperatures (30-60 ${ }^{\circ} \mathrm{C}$ ) has been investigated using potentiostatic polarization techniques. The results obtained were cross checked by the weight loss method.

\section{EXPERIMENTAL}

Specimen: Aluminium alloy $\mathrm{SiC}$ composite specimens having aluminium alloy 6061 as the matrix and containing $15 \mathrm{vol}$. \% of silicon carbide particles of mean diameter $25 \mu \mathrm{m}$ in the form of cylindrical bars of length $120 \mathrm{~mm}$ and diameter $40 \mathrm{~mm}$ are manufactured at Vikram Sarabhai Space Centre (VSSC) Trivandrum by Stir casting process with pouring temperature $700-710^{\circ} \mathrm{C}$, stirring rate $195 \mathrm{rpm}$, extrusion at $457^{\circ} \mathrm{C}$, extrusion ratio $30: 1$, direct extrusion speed $6.1 \mathrm{~m} / \mathrm{min}$ to produce $40 \mathrm{~mm}$ diameter cylindrical bars. This composite material has the chemical composition (\%wt): $0.25 \mathrm{Cu} ; 1.0 \mathrm{Mg}$; $0.60 \mathrm{Si} ; 0.20$ $\mathrm{Cr}$ and balance Al. The specimen with an exposed bottom surface area of 0.95 $\mathrm{cm}^{2}$ was polished with emery papers of different grades degreased with acetone and then rinsed with distilled water and finally dried in air.

Inhibitor: Ethyl-2-phenyl hydrozono-3-oxobutyrate was prepared as per the reported procedure ${ }^{12}$. Aniline $(0.01 \mathrm{~mol})$ was dissolved in dilute $\mathrm{HCl}(8 \mathrm{ml})$ and cooled to zero ${ }^{\circ} \mathrm{C}$. To this, a cold solution of sodium nitrite $(0.02 \mathrm{~mol})$ was added with stirring. The diazonium salt solution obtained was filtered into a cooled solution of ethylacetoacetate $(0.01 \mathrm{~mol})$ and sodium acetate $(0.15 \mathrm{~mol})$ in ethanol $(50 \mathrm{ml})$. The resulting yellow solid was filtered, washed and recrystallized. The purity of the compound was checked by the elemental analysis and melting point $\left(68{ }^{\circ} \mathrm{C}\right)$. The structural formula of the inhibitor compound is shown in Figure1.

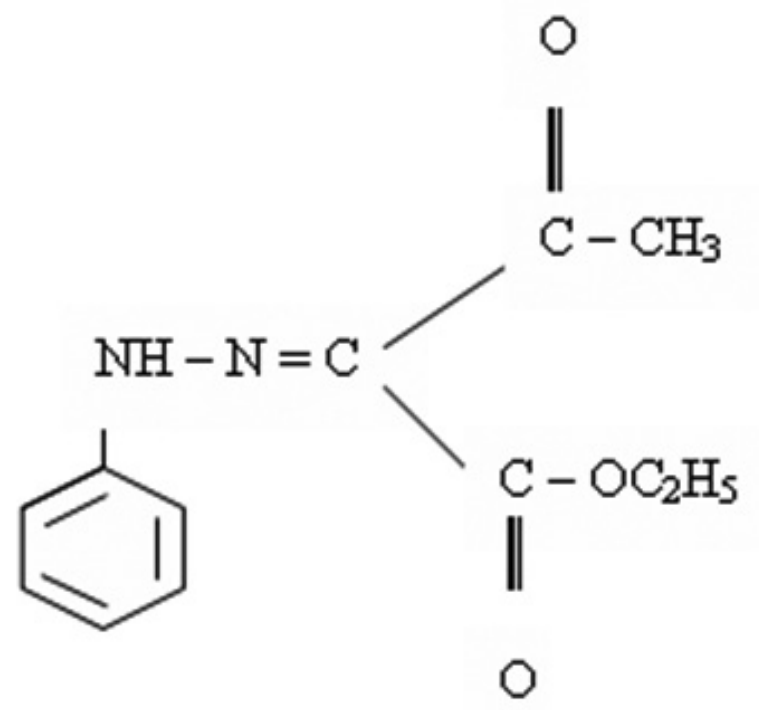

Fig. 1. Structural formula of ethyl-2-phenyl hydrozono-3-oxobutyrate.

Medium: Analytical reagent grade $\mathrm{HCl}$ (Merck) and double distilled water were used for preparing test solution of $0.1,0.5$ and $1 \mathrm{~N} \mathrm{HCl}$.

Tafel extrapolation studies: The polarization studies were performed 
using a Wenking Potentiostat and a three electrode cell system with the saturated calomel electrode as the reference electrode, platinum electrode as counter electrode and the specimen acting as the working electrode. Tafel extrapolation studies were made from $-250 \mathrm{mV}$ versus OCP to $+250 \mathrm{mV}$ versus OCP in steps of $20 \mathrm{mV}$ from the cathodic side and the corrosion currents were noted. The Tafel plots of potential versus log I were drawn and the corrosion current density $\left(I_{\text {corr }}\right)$ and the corrosion potential $\left(E_{\text {corr }}\right)$ were determined. The corrosion rate, the degree of surface coverage $(\theta)$ and the percentage inhibition efficiency $(\% I E)$ were calculated. The experiments were performed with 0.1 , 0.5 and $1 \mathrm{~N} \mathrm{HCl}$ at four different temperatures $\left(30-60^{\circ} \mathrm{C}\right)$. The temperatures were accurately maintained within $\pm 1{ }^{\circ} \mathrm{C}$. The results obtained by Tafel extrapolation technique were cross checked by linear polarization technique and weight loss method.

Weight loss method: Specimen coupons of $1 \mathrm{sq} \mathrm{cm}$ are exposed to $100 \mathrm{ml}$ of test solution for 6 hours. Before exposure the surface is polished with different grades of emery paper and rinsed with distilled water and acetone, then dried and finally accurately weighed. After exposure, again the specimen is gently polished, rinsed with distilled water and acetone, then dried and accurately weighed. The difference in weight gives the weight loss. Experiments were conducted with $0.1,0.5$ and $1 \mathrm{~N} \mathrm{HCl}$ in the presence and absence of inhibitor.

\section{RESULTS AND DISCUSSION}

The electrochemical parameters for the inhibition behavior of ethyl-2phenyl hydrozono-3-oxobutyrate on the corrosion of $6061 \mathrm{Al}$ alloy/SiCp composite in $0.1,0.5$ and $1 \mathrm{~N} \mathrm{HCl}$ solution were studied by potentiostatic polarization technique at four temperature levels. The results are presented in Table 1. It can be seen from the fitted results and the polarization curves (Figure 2) that there is a large negative shift in the corrosion potential $\left(E_{\text {corr }}\right)$ and a drastic reduction in the corrosion current density $\left(I_{\text { }}\right)$ and corrosion rate $(C R)$ values. The shift in corrosion potential in the negative direction indicates that oxobutyrate is an efficient cathodic inhibitor. The corrosion rate, the degree of surface coverage $(\theta)$ and the percentage inhibitor efficiency $(\% I E)$ were calculated by using the following relations ${ }^{13}$.

Table 1. Electrochemical parameters for the corrosion inhibition of $6061 \mathrm{Al}$ alloy/SiCp composite in $\mathrm{HCl}$ media.

\begin{tabular}{|c|c|c|c|c|c|c|c|c|c|c|}
\hline \multirow{2}{*}{$\begin{array}{c}\text { Temperature } \\
\left({ }^{\circ} \mathrm{C}\right)\end{array}$} & \multirow{2}{*}{$\begin{array}{c}\mathrm{C} \\
\mathrm{ppm}\end{array}$} & \multicolumn{3}{|c|}{$0.1 \mathrm{~N} \mathrm{HCl}$} & \multicolumn{3}{|c|}{$0.5 \mathrm{~N} \mathrm{HCl}$} & \multicolumn{3}{|c|}{$1 \mathrm{~N} \mathrm{HCl}$} \\
\hline & & $E_{\text {corr }}$ & $C R$ & $\% I E$ & $E_{\text {corr }}$ & $C R$ & $\% I E$ & $E_{\text {corr }}$ & $C R$ & $\% I L$ \\
\hline \multirow{5}{*}{30} & 0 & -690 & 34 & - & -690 & 2054 & - & -700 & 4520 & - \\
\hline & 25 & -700 & 7.4 & 78.2 & -750 & 440 & 78.6 & -780 & 1116 & 75.3 \\
\hline & 50 & -700 & 4.9 & 85.6 & -740 & 341 & 83.4 & -760 & 913 & 79.8 \\
\hline & 100 & -720 & 4.0 & 88.2 & -750 & 298 & 85.5 & -775 & 791 & 82.5 \\
\hline & 150 & -715 & 4.4 & 87.4 & -745 & 306 & 85.1 & -770 & 818 & 81.5 \\
\hline \multirow{5}{*}{40} & 0 & -700 & 82 & - & -690 & 3698 & - & -700 & 6573 & - \\
\hline & 25 & -750 & 20.6 & 74.9 & -745 & 822 & 77.8 & -760 & 2097 & 68. \\
\hline & 50 & -755 & 18.0 & 78.1 & -745 & 657 & 82.2 & -780 & 1683 & 74. \\
\hline & 100 & -765 & 14.4 & 82.4 & -750 & 575 & 84.5 & -780 & 1354 & 79. \\
\hline & 150 & -755 & 15.0 & 81.7 & -750 & 588 & 84.1 & -775 & 1374 & 79.1 \\
\hline \multirow{5}{*}{50} & 0 & -690 & 165 & - & -690 & 4930 & - & -720 & 7806 & - \\
\hline & 25 & -750 & 42.1 & 74.5 & -745 & 1242 & 74.8 & -780 & 2795 & 64.2 \\
\hline & 50 & -780 & 37.0 & 77.6 & -760 & 966 & 80.4 & -780 & 2279 & 70.8 \\
\hline & 100 & -780 & 26.4 & 84.0 & -760 & 858 & 82.6 & -785 & 1858 & 76.2 \\
\hline & 150 & -765 & 27.7 & 83.2 & -750 & 883 & 82.1 & -780 & 1889 & 75.8 \\
\hline \multirow{5}{*}{60} & 0 & -700 & 316 & - & -710 & 5546 & - & -700 & 11608 & - \\
\hline & 25 & -765 & 123 & 61.0 & -740 & 1581 & 71.5 & -780 & 4516 & 61.1 \\
\hline & 50 & -770 & 94.1 & 70.2 & -760 & 1231 & 77.8 & -790 & 3889 & 66.5 \\
\hline & 100 & -790 & 53.4 & 83.1 & -770 & 1076 & 80.6 & -790 & 2972 & 74. \\
\hline & 150 & -765 & 55.9 & 82.3 & -750 & 1115 & 79.9 & -780 & 3018 & 74.0 \\
\hline
\end{tabular}

Corrosion rate $(\mathrm{mpy})=\frac{0.1288 \times E q . w t \times I_{\text {corr }}}{D}$

where,

$I_{\text {corr }}=$ Corrosion current density in $\mu \mathrm{A} / \mathrm{cm}^{2}$.

Eq. $w t=$ specimen equivalent weight in $\mathrm{g}$.

$D=$ specimen density in $\mathrm{g} / \mathrm{cc}$

0.1288 is the metric and time conversion factor.

$$
\theta=\frac{\left(I_{\text {corr }}-I_{\text {cor (inh) }}\right)}{I_{\text {corr }}}
$$

Where, $\quad I_{\text {corr }}$ and $I_{\text {corrinh }}$ are the corrosion current densities in $\mu \mathrm{A} / \mathrm{cm}^{2}$ in the absence and presence of the inhibitor respectively.

$$
\% I E=\theta \times 100
$$

The inhibiton efficiency by weight loss method was calculated by using the following expression ${ }^{14}$.

$$
\% I E=\left(\frac{W-W_{i n h}}{W}\right) \times 100
$$

Where, $W$ and $W_{\text {inh }}$ are the values of weight loss of the specimen after immersion in test solution without and with inhibitor, respectively.

A comparison of the inhibition efficiency obtained from Tafel extrapolation technique, linear polarization technique and weight loss method at $30{ }^{\circ} \mathrm{C}$ are given in Table 2. The results obtained by the three methods are in good agreement.

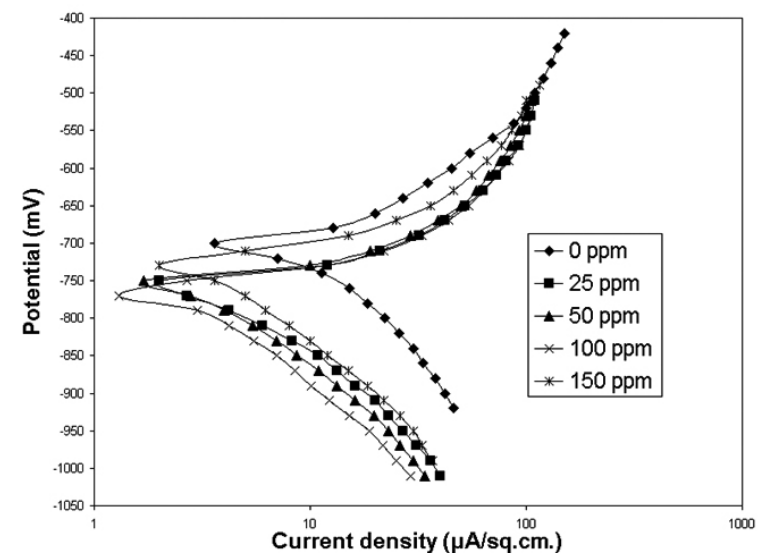

Fig. 2. Potentiostatic polarization curves for $\mathrm{Al}$ alloy/SiCp composite in $1 \mathrm{~N} \mathrm{HCl}$ with and without inhibitor at $30^{\circ} \mathrm{C}$. 
Table 2. Comparison of $\%$ IE values for all the three methods at $30{ }^{\circ} \mathrm{C}$

\begin{tabular}{|c|c|c|c|c|}
\hline \multirow{2}{*}{$\begin{array}{l}\text { Acid concentration } \\
(\mathrm{N} \mathrm{HCl})\end{array}$} & \multirow{2}{*}{$\begin{array}{l}\text { Inhibitor Concentration } \\
\text { (ppm) }\end{array}$} & \multicolumn{3}{|c|}{$\% I E$} \\
\hline & & $\begin{array}{c}\text { Tafel Extrapolation } \\
\text { Technique }\end{array}$ & $\begin{array}{c}\text { Linear Polarisation } \\
\text { Technique }\end{array}$ & $\begin{array}{l}\text { Weight Loss } \\
\text { Method }\end{array}$ \\
\hline \multirow{4}{*}{0.1} & 25 & 78.2 & 75.1 & 72.7 \\
\hline & 50 & 85.6 & 82.3 & 81.3 \\
\hline & 100 & 88.2 & 85.2 & 84.8 \\
\hline & 150 & 87.4 & 85.8 & 83.2 \\
\hline \multirow{4}{*}{0.5} & 25 & 78.6 & 75 & 74.5 \\
\hline & 50 & 83.4 & 82.6 & 79.4 \\
\hline & 100 & 85.5 & 85.2 & 84.3 \\
\hline & 150 & 85.1 & 84.5 & 83.5 \\
\hline \multirow{4}{*}{1} & 25 & 75.3 & 72.4 & 72.7 \\
\hline & 50 & 79.8 & 75.3 & 80.1 \\
\hline & 100 & 82.5 & 78.6 & 82.7 \\
\hline & 150 & 81.9 & 77.8 & 81.2 \\
\hline
\end{tabular}

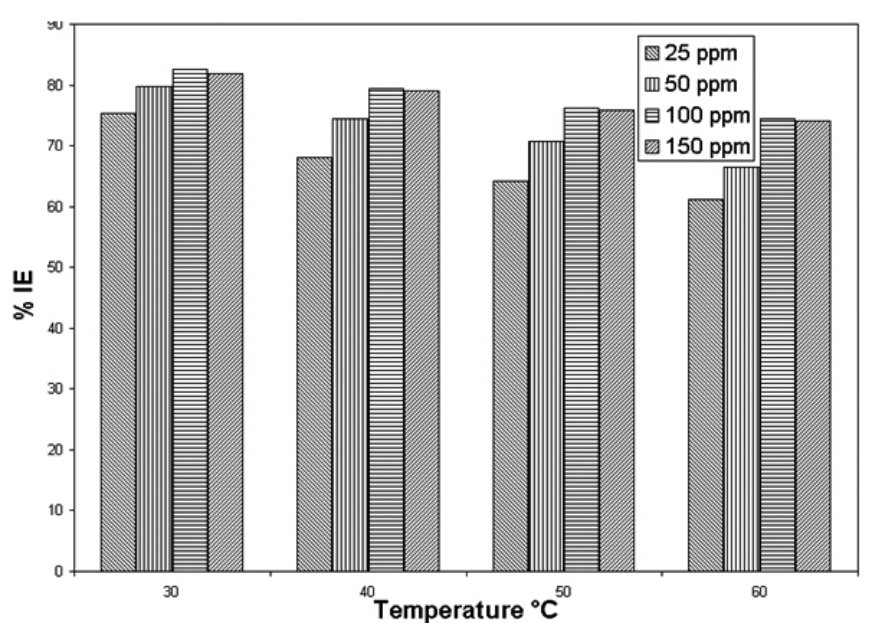

Fig. 3. Plot of temperature versus \% IE for oxobutyrate in $1 \mathrm{~N} \mathrm{HCl}$ medium

The $\%$ IE increases with increase in concentration of oxobutyrate (Table 1). The increase in $\% I E$ may be due to the blocking effect of the surface by both adsorption and film formation mechanism which decreases the effective area of attack. The variation of \% IE with temperature is shown in Figure 3 . The inhibition efficiency decreases with increase in temperature. The rise in temperature results in the increase in conductance of the aqueous acid medium and thereby increases the diffusion rate of hydrogen ions to the composite surface and hence the corrosion progresses faster at higher temperatures. The results indicate that oxobutyrate is an effective inhibitor with maximum IE value of $88 \%$ in $0.1 \mathrm{~N} \mathrm{HCl}$ containing $100 \mathrm{ppm}$ of inhibitor.

The surface analysis of $6061 \mathrm{Al}$ alloy $\mathrm{SiCp}$ composite was carried out using scanning electron microscope (JEOL Model 8340LA). The scanning electron micrographs of a fresh specimen of $6061 \mathrm{Al}$ alloy $\mathrm{SiCp}$ composite is shown in Figure 4a. The micrographs for the specimens immersed in $1 \mathrm{~N}$ $\mathrm{HCl}$ solution at $30^{\circ} \mathrm{C}$ in the absence and presence of inhibitor are shown in Figures $4 \mathrm{~b}$ and $4 \mathrm{c}$ respectively. The corrosion of $\mathrm{Al}$ alloy $\mathrm{SiCp}$ in $\mathrm{HCl}$ medium is presumably due to the anodic dissolution either at the grain boundaries or at the metal-media interface. It is seen from the Figure $4 \mathrm{c}$ that the surface of $6061 \mathrm{Al}$ alloy SiCp exposed to inhibited solution is smoother than that exposed to uninhibited acid solution (Figure 4b). These observations suggest that the inhibitor forms a protective layer on the composite surface, which prevent the attack of acid on the surface.

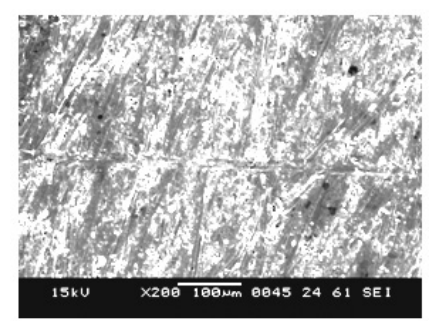

(a)

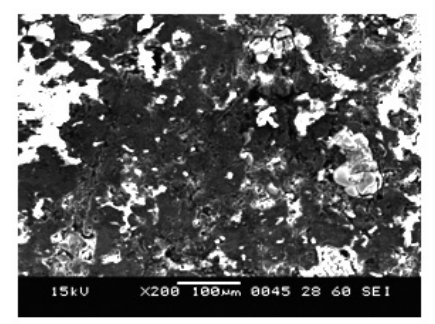

(b)

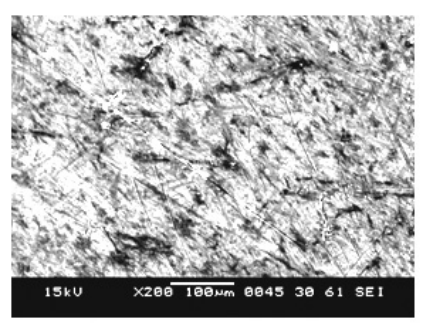

(c)

Fig. 4. The scanning electron micrographs of $\mathrm{Al}$ alloy SiCp composite

(a) Fresh specimen, (b) Specimen exposed to $1 \mathrm{~N} \mathrm{HCl}$, (c) Specimen exposed to $1 \mathrm{~N} \mathrm{HCl}$ containing $100 \mathrm{ppm}$ of oxobutyrate.

To understand the mechanism of corrosion inhibition, the adsorption behavior of the inhibitor compound on the composite surface must be known ${ }^{15}$. The surface coverage values for different concentrations of oxobutyrate from the acid solution were calculated. The surface coverage values $(\theta)$ were tested graphically by fitting to suitable adsorption isotherm. The plot of $\theta$ versus $\log c$ (Figure 5) for different concentrations of oxobutyrate shows a straight line indicating that the adsorption of the compound on the composite surface follows Temkins adsorption isotherm. The applicability of Temkins adsorption isotherm verifies the assumption of mono-layer adsorption on a uniform homogeneous composite surface with an interaction in the adsorption layer ${ }^{16}$. 


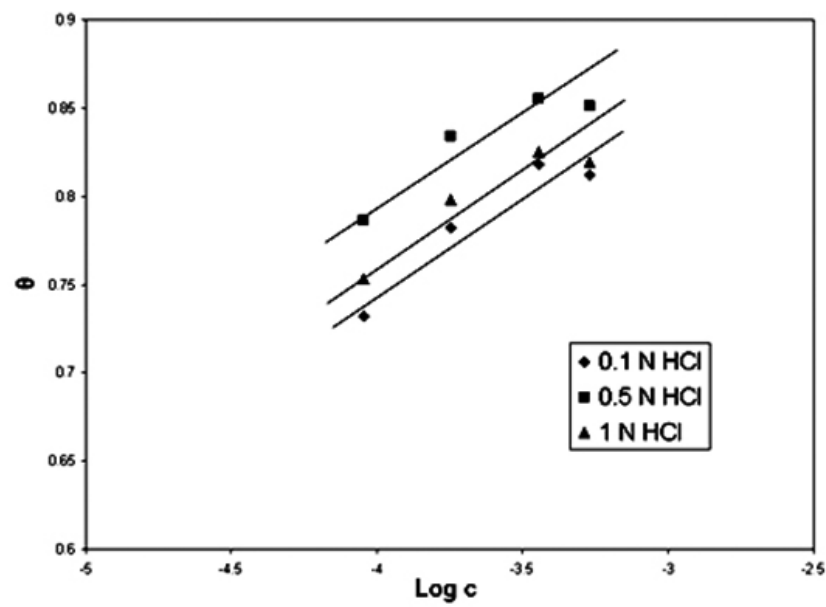

Fig. 5. Temkins adsorption isotherm for oxobutyrate in $\mathrm{HCl}$ medium at $30{ }^{\circ} \mathrm{C}$.

To further confirm the adsorption behavior of the inhibitor, Langmuir adsorption isotherm was constructed. Plots of $\log [\theta /(1-\theta)]$ versus $\log c$ are found to be linear (Figure 6) suggesting that the molecules are adsorbed over the metal surface forming a barrier, which prevents the contact of the metal with electrolyte ${ }^{17,18}$.

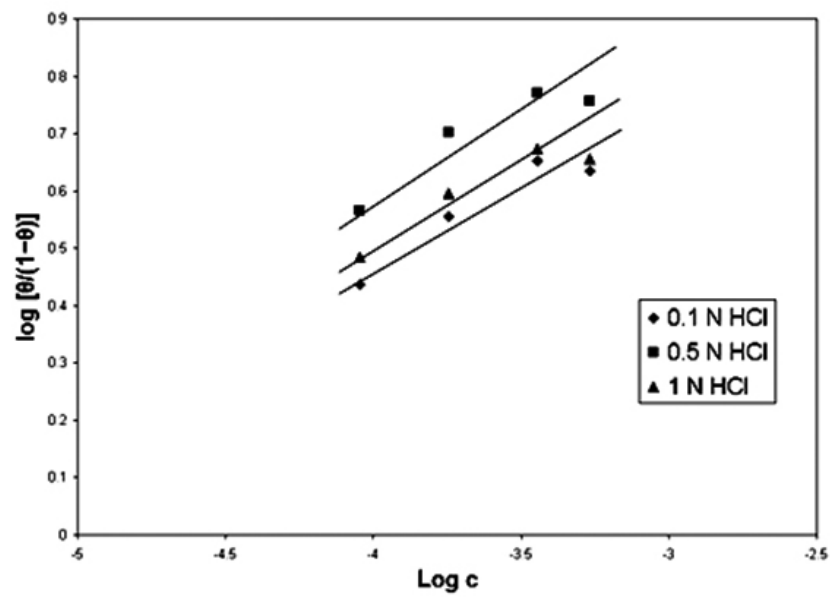

Fig. 6. Langmuir adsorption isotherm for oxobutyrate in $\mathrm{HCl}$ medium at $30{ }^{\circ} \mathrm{C}$.

The thermodynamic parameters for the corrosion of $\mathrm{Al}$ alloy/SiCp composite in the presence of oxobutyrate are studied (Table 3 ). The equilibrium constant $(K)$ is determined by the relation:
Table 3 - Equilibrium constant, Activation energy $\left(E_{a}\right)$ and Gibb's Free energy of adsorption $\left(\Delta \mathrm{G}_{\mathrm{ads}}\right)$ for the corrosion of $6061 \mathrm{Al}$ alloy/SiCp Composite in $\mathrm{HCl}$ media .

\begin{tabular}{|c|c|c|c|c|}
\hline $\begin{array}{c}\text { Acid } \\
\text { concentration } \\
\text { (N HCl) }\end{array}$ & $\begin{array}{c}\text { Concentration } \\
\text { of } \\
\text { Oxobutyrate } C \\
(\mathrm{ppm})\end{array}$ & $\begin{array}{c}\text { Equilibrium } \\
\text { constant, } \\
\mathrm{K}\end{array}$ & $\begin{array}{c}\mathrm{E}_{\mathrm{a}} \\
(\mathrm{kJ} / \\
\left.\mathrm{mol}^{-1}\right)\end{array}$ & $\begin{array}{c}-\Delta G_{a d s} \\
\left(\mathrm{~kJ} / \mathrm{mol}^{-1}\right)\end{array}$ \\
\hline \multirow{4}{*}{0.1} & 0 & - & 62.3 & - \\
\cline { 2 - 5 } & 25 & 39,946 & 78.6 & 36.8 \\
\cline { 2 - 5 } & 50 & 33,025 & 82.6 & 36.3 \\
\hline \multirow{4}{*}{0.5} & 100 & 20,808 & 72.5 & 35.2 \\
\cline { 2 - 5 } & 150 & 12,874 & 71.1 & 34.0 \\
\cline { 2 - 5 } & 0 & - & 27.8 & - \\
\cline { 2 - 5 } & 25 & 40,901 & 35.8 & 36.9 \\
\hline \multirow{4}{*}{1} & 100 & 27,912 & 35.9 & 35.9 \\
\hline & 150 & 16,415 & 35.9 & 34.6 \\
\hline & 25 & - & 26.4 & - \\
\cline { 2 - 5 } & 50 & 21,947 & 40.5 & 35.3 \\
\hline & 100 & 13,123 & 37.0 & 34.0 \\
\hline & 150 & 8,398 & 36.5 & 32.9 \\
\hline
\end{tabular}

$$
K=\frac{\theta}{c(1-\theta)}
$$

Where $\theta$ is the degree of surface coverage on the metal surface and $c$ is the concentration of the inhibitor in $\mathrm{molL}^{-1}$

The free energy of adsorption $\left(\Delta G_{\text {add }}\right)$ is calculated from the following equation ${ }^{19,20}$.

$$
\Delta G_{a d s}=-R T \ln (55.5 K)
$$

Where 55.5 is the concentration of water in solution in molL ${ }^{-1}$ and $\mathrm{T}$ is the temperature in Kelvin.

The negative values of $\Delta G_{\text {ads }}$ indicate spontaneous adsorption and strong interaction of inhibitor molecules on to the surface of the composite. The $\Delta G_{\text {ads }}$ values obtained for $100 \mathrm{ppm}$ of oxobutyrate were less than $40 \mathrm{~kJ} \mathrm{molL}^{-1}$ nd this indicates that the inhibition is governed by physical adsorption mechanism.

\section{CONCLUSIONS}

1. Oxobutyrate acts as an efficient cathodic inhibitor for corrosion of $6061 \mathrm{Al}$ alloy/SiCp composite in $0.1-1 \mathrm{~N}$ hydrochloric acid medium.

2. The corrosion rate decreases with increase in inhibitor concentration and increases with rise in temperature in the presence of the inhibitor.

3. The adsorption of the compound on the surface of $\mathrm{Al}$ alloy/SiCp composite was found to obey both Temkins and Langmuir adsorption isotherms and governed by physical adsorption mechanism.

4. The inhibition efficiency obtained by polarization techniques and weight loss method are in good agreement.

\section{ACKNOWLEDGEMENTS}

The authors are thankful to Brig. Dr. S. S. Pabla, Director and Dr. N. Y. Sharma, Head, Department of Mechanical Engineering, Manipal Institute of Technology for providing the facilities.

\section{REFERENCES}

1. G. O. Avwiri, F. O. Igho, Mater. Lett. 57, 3705, (2003).

2. K. A. Lucas, H. Clarke, Corrosion of Aluminium based metal matrix composites, Research studies Press Ltd., Somerset, U.K.,1993.

3. S. Wernick, R. Pinner, P. G. Shasby, The surface treatment and finishing of Aluminium and its alloys, 5 ${ }^{\text {th }}$ edn., Vol 1, Ch 5, 1987. 
4. D. W. Berkeley, H. E. M. Sallam, H. Nayeb-Hashemi, Corros. Sci. 40, 141, (1998).

5. G. Schmitt, Br. Corros. J. 19, 165 (1984).

6. B. Mernari, H. Elattari, M. Traisnel, F. Bentiss, M. Legrance, Corros. Sci. 40, 391, (1998).

7. K. Obesegun Abiola, N. C. Oforka, S. S. Angeye, Mater. Lett. 58, 3461, (2004).

8. S. Bilgic, M. Sahin, Mater. Chem. Phys. 70, 239, (2001).

9. H. F. Finley, N. Hackerman, J. Electrochem. Soc. 107, 259, (1960).

10. A. Suma Rao, Padmalatha, Jagannath Nayak, A. Nithyananda Shetty, J. Met. Mater. Sc.47, 51, (2005).

11. A. Suma Rao A, Padmalatha, Jagannath Nayak, A. Nithyananda Shetty, K. R. Hebbar, National conference on corrosion and corrosion control, METCORR - 2005, NITK, Surathkal, India p.100.

12. M. Arun Isloor, PhD Thesis, "Studies on the synthesis and Biological activity of some pharmaceutically important Heterocyclic compounds", Mangalore University, India, August 2001, p.104.
13. M. A. Quraishi, M. Z. A. Rafiquee, Sadaf Khan, Nidhi Saxena, J. Corros. Sci. and Engg. 10, (2006).

14. M. Abdallah, Corros. Sci. 44, 717, (2002).

15. N. Al-Andis, E. Khamis, A. Al-Mayouf, H. Aboul-Enein, Corros. Prev. Control 42, 13, (1995).

16. A. E. Stayomova, E. I. Sokolova, S. N. Roichra, Corros. Sci. 39, 1595, (1997).

17. J. G. N. Thomas, in Corrosion: Vol.2, Edited by L. L. Shreir, R. A. Jarman, G. T. Burstein, Butter Worth-Heinemamn, 2000.

18. A. Nahle, Bull. Electrochem, 17-5, 221, (2001).

19. I. K. Putilova, S. A. Balezin , Y. P. Borasanic, Metallic Corrosion Inhibitors, Pergomeon Press, Oxford, 1960.

20. M. A. Quaroishi, R. Sardar, Indian J. Chem. Technol. 11, 103, (2004). 